Renan having installed in front of the eyepiece a prism which reversed the direction of apparent movement of the stars, either in right ascension or declination.

The "Supplément à l'Histoire Céleste de Lalande" is undergoing revision, and the positions of 2250 stars are required to be re-observed, each three times by meridian observations. Since April 1S93, sixty series, comprising about 1000 stars of the catalogue, have been obtained.

The risume of the meridian observations made during the year shows that the instruments were by no means idle, no less than 17,248 observations having been made. The résumé of the planets observed during the same period gives the total number as 556 .

Equatoriaux Coudes. - The Jarge equatorial has been re. ceiving several alterations and additions, and it is hoped to maintain the position of a fixed or movable star on the same part of a photographic plate with an approximation of $\mathrm{O}^{\prime \prime} \cdot 2$ nearly. The small coude has been the means of effecting the complete measurements of 186 double stars, besides some observations of minor planets, comets, occultations, \&.c.

The Equatorial in the West Tower.-This instrument is under the direction of M. Bigourdan, who, with M. Faye, were away observing the total eclipse of the sun at Sénégal. During their stay there, fifteen lunar culminations for longitude and four series of observations for latitude were made, besides metecrological observations and four independent determinations of the rela. tive intensity of gravity. The solar observations, among other things, consisted in observing the four contacts, and searching round the limb of the sun for any small bodies that might be visible.

The observations made with the equatorial above referred to consisted of measurements of 280 double stars, besides those of comets, occultations, \&c.

The equatorial in the east tower, under M. Callandreau's direction, has been devoted chiefly to observations of minor planets.

In the departments where photography is employed, MM. Henry have obtained, among other results, 169 clichés for the catalogue of the Carle du Ciel, twenty-nine large clichés of the moon, enlarged directly eighteen times, these latter marking "? un progrès très sensible sur les résultats obtenus antérieurement."

The "Bureav des Mesures des Clichés du Catalogue," under MIdle. Klumpke's supervision, is now supplied with two machines. The total number of stars measured in the twelve months amount to 27,750 ; of these $26,83 \mathrm{I}$ were measures of stars, 343 measures of double stars, and 32 planetary measures.

The meteorological observations and the hour service have been regularly continued, the latter without any failure during the entire year.

In the spectroscopic department, M. Deslandres has been continuing the researches on the sun and stars; but much time was devoted to the preparations for the observations of the total eclipse of the sun last year. The results obtained during the eclipse consisted of twenty-two photographs of the corona. Some of the negatives show luminous jets from the corona extending to a distance of two diameters. The ultra-violet spectrum of the corona has been traced up to the limit of the ordinary solar spectrum, and in addition fifteen lines have bcen observed in the new region. In the researches concerning the rotation of the corona, it has been found that one of the negatives shows the spectra of two points of the corona, situated at the extremity of an equatorial diameter and $10^{\prime}$ from the solar limb, placed side by side. The bright $\mathrm{H}$ and $\mathrm{K}$ lines of calcium present a slight displacement corresponding to a difference of velocity of 5 to 7.5 kilometres. M. Deslandres admits that the solar corona is animated with a motion of rotation, the angular velocity of which corresponds with that of the sun.

Other spectroscopic work being continued is that of the study of the radial velocities of prominences and stars.

\section{THE CHEMISTRY OF CLEANING.'}

$A S$ a great city grows, and the agglomeration of struggling humanity increases, such questions as the disposal of sewage and other waste matter rise from comparative insignifi gance into problems of almost insurmountable difficulty; and

I A lecture delivered at the London Institution, by Prof. Vivian Lewes. whilst we are able to put the burden of cleansing our towns upon the urban authorities, the responsibility of keeping our homes and bodies in a condition of at least sanitary cleanliness devolves upon the individual, and a knowledge of the causes of dirt and the methods by which it can be removed, cannot be regarded as devoid of interest, or at any rate utility.

Before we can cleanse, we must have dirt to remove, and this prime factor of our subject naturally must claim our first attention.

Dirt has been variously defined: a great statesman has spoken of it as " matter out of place," poets have christened it the "bloom of ages," whilst more matter-of.fact individuals have been content to look upon it as something which causes an infinite amount of trouble in the household, and leads to the consumption of much soap and water. If, however, we divest our mind of prejudice, and approach the subject of dirt from a scientific point of view, we shall find a silver lining to the grimy cloud, and shall have to admit that a wondrous store of interest is to be found in the dust with which the housemaid wages perpetual war, and which when glued by nature to our skins, requires special methods for its removal.

Observation shows that in our town houses, only a very short interval of time is needed to cause a considerable deposit of dust upon any horizontal surface, whilst vertical surfaces and draperies, especially if their surface be rough, also accumulate a considerable quantity, although of a lighter and more finely divided kind. TVe also find that this dust is borne to its resting place by the air which penetrates from the outer atmosphere, and that its deposition is caused by the comparative condition of rest insured to it by the absence of wind or violent currents.

The presence of these air-borne particles of solid matter can be made visible in any town by allowing a bean of sunlight or a ray from an electric lantern to pass through the air of a darkened room. If the room be filled with air previously filtered by passing it through cotton wool, the beam of light is invisible until it strikes the opposite wall; but if the air be unfiltered, the path of the beam is mapped out by the suspended matter reflecting and dispersing portions of it, and so becoming visible to the eye as "the motes in the sunbeam."

The heavier the nature of the particles, the more quickly will they settle, with the result that the dust on horizontal surfaces, such as the tops of sideboard, piano, and mantel-board, may. be expected to differ somewhat from the lighter form, which has continued to float until contact with vertical surfaces has brought it to rest.

These particles of dust are composed of matters of the most varied nature, and will be found, when collected, to consist partly of mineral and partly of organic substances, namely, siliceous and carbonaceous matters, hair, epidermis from the skin, pieces of vegetable fibre, pollen from various plants and grasses, the sporidia of fungi and bacteria.

The heavier portions of the dust are found to contain groundup siliceous matter, pulverised by traffic in the road; small particles of salt carried inland by winds from the sea, together with sulphate of soda, with other impurities of a local character. If a sample of dust be collected and carefully ignited, the organic matter will be burnt away, and any ammonium salts volatilised, whilst the mineral portion will be unacted upon; and in this way it has been shown that more than one half of the suspended matters in the air are of organic origin, a large portion of this organic matter consisting of germs which are capable of setting up fermentation, disease, and decay.

It is only within the last few years that the importance of the work done by the solid particles of dust floating in the air has been recognised, and it is to Pasteur that we owe the knowledge that these germs set up the various processes of organic decay.

Pasteur collected the lightest portions of dust, which are left floating in the air after the heavier portions have settled down, by gently drawing air through a plug of soluble collodion cotton and after he had collected sufficient dust in this way, he dissolved the cotton in a mixture of alcohol and ether, and examining the residual particles under the microscope, was able to show the presence of a large and variable number of organisms obtained from the atmosphere.

He also found that solutions of sugar mixed with beer yeast, and left exposed to the air, rapidly decomposed. If, however, the solution was kept in contact with air, that had been previously heated, it would remain unchanged for months, but de-

No. I 289 , VOL. 50] 
composition was started in a few hours if some of the germs collected from the air were added to it.

If a pot of ordinary paste, after being used, is placed on a shelf for a few days, the surface will be found coated with a fine crop of mould or mildew. On examining this mould under the microscope, it will be seen to somewhat resemble a bed of rushes; after a few more days, some of these:rush-like filaments will have developed little pods, not unlike poppy-heads, and after the lapse of another week the pods will have split open and myriads of seeds or germs will have poured forth into the air to carry on nature's cleansing work, for these germs possess the power of setting up the process of decay, by which the waste matter derived from vegetable sources is once again resolved into the water vapour and carbon dioxide used by nature as the foundation of all organic creations.

Decay and putrefaction are the great factors of change which nature utilises for removing the waste products of animal and vegetable life, and for once more bringing them into a condition in which living things can again assimilate, and use them for huilding up their tissues and carrying on their functions. Without decay, the dead animal and yegetable matter would remain choking the face of nature, and life would be impossible, because the food of life would be cut off; and it is the alınost imperceptible germs floating in the air which start this marvellous natural action, germs so minute that it requires the strongest microscope to detect them, yet so potent that the whole balance of life hanzs on their existence.

These facts show us that not only has dust a most marvellous hi-tory, but that in it nature has disguised her most important factor for cleaning the face of the earth from waste matter of hoth mineral and vegetable origin.

The surface soil when mixed with water gives the mud which dirties our hoots, and forms clots on the train of our skirts; but this, as well as the dust which has settled in our living rooms, and merely clings mechanically to the surfaces upon which it has deposited, may be removed by such simple physical means as the duster and brush. When dust has found its way into a fabric such as a carpet, it requires considerable force to again dislodge it, and this is applied by means of the broom, but in vigorous sweeping we find that the largest proportion of the dist is driven up into the air, only to resettle once again on other surfaces, so that although we can make the nuisance "move on," we do not in this way remove it, and experience has laught our servants that wet tea-leaves scattered on the carpet before sweeping lessen this evil In some cases, instead of using this method, it has been argued that it must be the moisture which acts in preventing the raising of the dust, and the carpet has been sprinkled with water. This converts the dust into mud, which remains fixed in the fabric whilst the sweeping is going on, but as soon as the water has evaporated from it, again reasserts its right of rising as dust.

When, however, wet tealeaves, damp sawdust, or even moistened sand is scattered over the surface to be swept, the du-t when dislodged adheres to the moistened substance and is removed. In choosing moist bodies for this purpose, the only points to consider are that they must have no staining action on the carpet, must not be too wet, and must not be so finely grained as to sink into the fabric, nor so clinging as to resist easy removal by the broom.

It is manifest, however, that the mechanically beld dirt which we have been considering, differs very considerably from the dirt on our skins, and on linen in contact with our bodies, which although derived from the same sources as the dust on the furniture, resists any ordinary mechanical process for its removal, and rinsing dirty hands or linen in cold water has but little cleaning effect, whilst if the hands are afterwards dried in the usual way, a transfer of a portion of dirt to the towel takes place.

If we carefully notice the portions of our shin and shirt which become most soiled, we at once observe that it is where the skin is exposed to air, whilst the linen, which is in contact with both air and skin, becomes dirty more quickly than when exposed to either alone.

The part played by the atmosphere is made clear by the facts which we have already been considering, but the action of the skin introduces a new and most important factor. For the healthy carrying on of the functions of life, nothing exceeds in importance the skin with which our body is covered. We may live for days without giving our stomach any work to do, the liver may cease action for several days before death ensues, but it is impossible to survive for the same length of time if the functions of the skin are entirely stopped.

The skin not only plays an important part in throwing off and getting rid of waste matter from the system, but it is also credited with being an important auxiliary to our lungs, and experiments have clearly shown that if the skin of animals be coated in such a way as to completely stop its action, a very few hours will bring about death. Indeed the experiment has heen once accidentally tried on a human being, a child gilderl all over to represent a statue having died in a few hours all the symptoms pointing to suffocation as being the cause of death.

If we examine the structure of the skin, we find that it is built up of two distinct layers, an outer skin called the cuticle or epidermis, and an inner termed the cutis or dermis. A third layer intermediate between these two, used to be looked upon as a third skin, but more recenily has been recognised as being only a transition form of the ouler skin.

The cuticle or outer skin consists of several fine layers of scales which gradually assume a more rounded and granular form the deeper one gets into the cuticle. These rounded granules form the middle skin of the old observers, and as the nuter portion of the cuticle roughens and scales off as scurf, these granules gradually flatten and form the new surface to the outer skin, and we differ therefore from other scaly reptiles by being continually in a condition of renewing our skin, whilst most reptiles and fish cast their scaly covering in on operation.

No nerves or blood-vessels find their way into this outer skin, as may be seen when it becomes detached from the inner skin in the formation of a blister, the outer portion of which is devnid of sensation.

The lower or true skin varies in thickness, being thicker in the palm of the hand and sole of the foot, where most resistance is needed.

When we look at the skin of the hand, we notice delicate grooves in it, which examined through a magnifying glass are seen to be pierced with small orifices, and if the hand be warm, minute shining drops of perspiration will be seen issuing from them.

The glands for the secretion of the perspiration are set in the lower side of the inner skin, and are in connection with the capillary network of blood-vessels, which cover the surface of the body. The gland or duct which conducts the perspiration to the surface of the skin is about a quarter of an inch in length, and is straight in the true skin, but becomes spiral whilst traversing the outer skin. Over 3500 of these small ducts have been found to exist in a single square inch of the skin, and it has been computed that the aggregate length of the sudoriferous ducts in the body of an ordinary-sized man is about twenty-eight miles.

These little glands and ducts perform the important function of throwing off the moisture produced during the combustion of waste tissue, by the blood-borne oxygen of the body, and secrete about 23 ounces of perspiration in the twenty-four hours, which under ordinary conditions evaporates, without our noticing it, into the air, but under conditions of considerable exertion or unusual heat, accumulates as beads of perspiration.

The throwing off of the perspiration and its evaporation on the skin, is a beautiful natural contrivance for regulating the temperature of the body, as the conversion of the perspiration into vapour renders latent an enormous amount of heat, which being principally derived from the body keeps it in a comparative state of coolness, even when subjected to high temperatures.

That this is so, is proved by the fact that a bath heated to $120^{\circ} \mathrm{F} .\left(=49^{\circ} \mathrm{C}\right.$. $)$ is almost unbearable, because the evaporation from the surface of the shin is checked, whilst it is perfectly possible for a person with the skin fully exposed to go into an oven and remain there for some time at a temperature of $325^{\circ} \mathrm{F}$. or $162^{\circ} \cdot 8 \mathrm{C}$., at which temperature a beef-steak can be cooked, and it can be clearly noticed in a Turkish bath, that although there is a feeling of oppression at first, the temperature of the hot room can readily be borne as soon as perspiration begins to flow.

In the 23 ounces of liquid so secreted in the course of the twenty-four hours, there will be found rather more than an ounce of solid matter, which is left when the liquid portion of the perspiration-evaporates, and tends to clog the pores of the skin, and it is the removal of this by the morning tub and

No. I 289 , voL. 50$]$ 
rough towel, which is responsible for a considerable portion of the refreshing influence of the British bath.

Besides these sudoriferous glands, however, there is a second set, called the sebaceous glands, the ducts of which are spiral, and open generally into little pits, out of which the fine hairs which stud the skin grow, and these glands secrete an oily or waxy substance, which nourishes the hair, and also keeps the outer skin smooth and pliant. This waxy substance is developed in largest quantity inside the ear, where it serves to protect the more delicate portions of that organ, and next to the ear, these glands are found most abundantly on the face and other portions of the body which are exposed to external influences and friction.

It is the presence of this oily secretion which holds the dirt glued to the skin, and being also rubbed off on the inside of the wristbands and collars of our shirts, causes these portions of our linen to become the most soiled. IVe may look upon this form of dirt, therefore, as being glued on to the surface by oleaginous materials, which being insoluble in water resist any mere rinsing, and the most important function of our cleansing materials is to provide a solvent which shall be able to loosen the oil, and so allow of the removal of dirt from the skin.

The skin, however, is not the only source of oily matter, and in all fibres of animal origin more or less fat is to be found, which although not in sufficient quantity to play any very im. portant part in the fixation of dirt, still adds its iota to the general result.

We notice, moreover, that the air of a big town has a far greater dirtying effect than country air, this being partly due to the fact that the number of solid particles per cubic foot of atmosphere are greatly reduced, but chiefly because country air does not contain certain products of incomplete combustion, which are to be found in all large towns.

In London we annually consume some six million tons of bituminous coals, and if we examine the smoke which escapes up our chimneyduring the imperfect combustion which the cuals undergo in our fire-grates, we find that not only will that smoke contain small particles of unconsumed carbon in the form of blacks or soot, but also a considerable quantity of the vapour of condensible hydrocarbon oils, which depositing on the surface of the solid particles of floating dirt, gives them an enhanced power of clinging to any surface with which they come in contact.

If we have a heavy fall of snow in London, as the snow melts it leaves a black deposit, which is formed of the solid particles with which the snow bas come in contact in its passage through the air, and a recent analysis of a deposit of this character, collected on the glass roof of an orchid house at Chelsea. gives a very good idea of the constituents of these solid im. impurities.

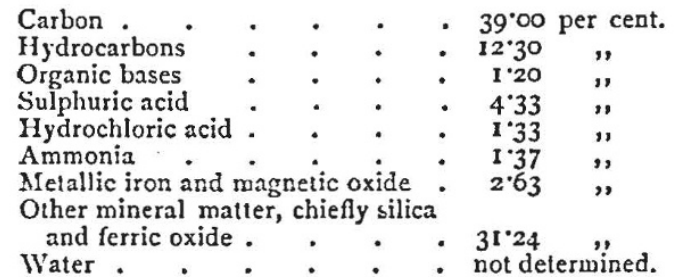

Hydrocarbon oils of this character are not as a rule affected by the solvents which we utilise for loosening the dirt which is held to our skin by animal grease; but there is no doubt that the dirtying influence of town air is greatly increased by their presence.

If we take any grease of vegetable or animal origin, we find that it can be dissolved in liquids containing free alkalies, this term being applied to the compounds formed by water with the soluble metallic oxides, which, when dissolved in water, give solutions having a soap.like taste, affecting the colour of vegetable extracts, such as that obtained by the red cabbage, and possessing the power of neutralising the acidulous properties of the cumpounds we call acids.

If we take two metals discovered by Sir Humphrey Davy in 1807, potassium and sodium, and expose them to dry pure air they rapidly become converted into a white powder by absorb. ing oxygen from the atmosphere, and form compounds which we term respectively oxide of sodium and oxide of poiassium. These oxides, when dissolved in water, enter into combination No. I 289 , voL. 50] with a portion of it, producing sodic hydrate and potassic hydrate, two substances which have pre-eminently the properties which we term alkaline, and which exert a strong solvent action upon all forms of animal and vegetable grease.

These solutions exercise a wonderful power of cleansing upon the grease-bound particles of dirt which veil our skin, but so strong is their solvent power upon animal membrane, that not only do they dissolve fatty matter, but also the cuticle itself, so that they are manifestly unfitted for removing dirt from a tender skin, and we are forced to look further afield for a grease solvent.

If instead of dissolving our sodic and potassic oxide in water we had left them exposed to ordinary air, we should have found that they gradually attracted from the atmosphere a gas called carbon dioxide, which exists in all air to the extent of 4 parts in 10,000 , and that by combining with this gas they became converted into sodic and potassic carbonates, bodies which we call salts, and which, although not so violent in their action upon the skin, will retain to a certain extent their solvent action on fatty matters.

The carbonates of sodium and potassium are found in the ashes of many vegetable and animal substances, and in the earliest records $\mathrm{which}$ have been discovered, we find mention of the cleansing power of wood ashes, the ashes of certain marine plants, sea-weed, and "natron," which is an alkaline efflorescence from some kinds of soil ; nor has the use of ashes for this purpose entirely died out at the present time.

It was only in 1884 , that during some structural alterations in Rome, an old tomb was broken into, and the ashes which it contained removed by one of the workmen, who conveyed them home to his wife, as an offering towards the next washing-day, whilst a few days later the antiquarians were horrified to discover that they were the remains of the Emperor Galba, cremated some eighteen centuries before, which had been put to such practical use.

As early as A.D. 69, however, we find that the elder Pliny mentions another form of cleansing material made from tallow and ashes, the components most recommended being goat's suet and the ash of beechwood; whilst the ruins of Pompei were found to contain a fairly perfect soap factory.

Although soap and Christianity date from the same period, it was only at the commencement of this century that the classical researches of Chevreul on the constitution of fats, gave the key to the reactions taking place during its formation, whilst even at the present time we probably only know a true explanation of part of the actions which lead to its cleansing effect upon the skin.

If we take sulphuric acid diluted with water, we find that it has certain well-marked characteristics, which leave no room for doubting its acidulous nature, and if we pour a few drops of it into the violet-coloured solution obtained by boiling sliced red cabbage in water, the violet solution at once becomes bright red. On repeating this experiment with the violet cabbage solution, and a few drops of sodic hydrate solution, we obtain a vivid green colour, and now on mixing the solution rendered red by the acid, and the second nne turned green by the alkaline base, we once more obtain the original violet colous, and on examining the solution can find no trace of either acid or alkali, but can distinguish the presence of a compound called sodic sulphate, which can be obtained in the crystalline form by concentrating the solution, and such a com pound formed by the union of an acid and a base, we are in the habit of calling a salt. During the combination of the sulphuric acid and sodic hydrate to form sodic sulphate, we also had water being formed, which, like the neutral salt, had no action upon our coloured solution. If we had carefully weighed our sulphuric acid and the sodic hydrate, we should have found that it is only in certain definite proportions that they unite to give a solution without effect on the vegetable colouring matter, and we might sum up our experiments on the combination of these two substances as follows :-

Acid.

Sulphuric acid Base.

A salt.

Vater. $9^{5}$ parts by weight. ${ }_{80}$ parts by weight. $={ }_{142}$ parts by weight. ${ }^{+}$by weight.

And if we take crystals of sodic sulphate, and dissolve them in water, we can decompose them once more into sulphuric acid and sodic bydrate by the aid of galvanic electricity.

My aim in this experiment has been to impress upon you that a salt is a compound formed by the union of an acid and a base, 
and one of Chevreul's greatest discoveries was that in tallowthe fat of oxen or sheep-you had a salt of organic origin, from which by decomposing the tallow with heated steam, you could obtain the sweet viscous liquid "glycerine," which played the part of base in the compound, and two acidulous compoundsone a lustrous white wax, called stearic acid, and the other an oil called oleic acid.

Now a salt can have its base replaced by another base. If I take two soluti.uns, the one containing sulphate of copper, and the other chloride of iron, and add to each sodic hydrate, decomposition takes place in each case, sodic sulphate is left in solution, and the hydrates of copper and iron being insoluble in water, separate out as precipitates.

In the same way, if we add sodic hydrate to tallow, glycerine separates out, and two salts-sodic oleate and sodic stearateare formed, a process which we call saponification, as the two sodium salts are "soaps."

It is not necessary to use tallow; any vegetable or animal fat or oil will give reactions of a similar character, and it may be broadly stated that soap is formed by the action of sodic or potassic hydrate upon fats or oils which contain fatty acids.

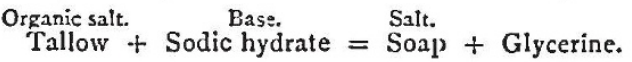

It is only potassic and sodic bydrates which can be used for ordinary soap-making, as the soaps formed by the combination of other metallic hydrates with the fatty acids are insoluble in water, ind thereiore useless for delergent purposes.

The soap formed by using sodic hydrate has the property of setting hard, and all the ordinary forms of washing-503p contain sodium as the base; the potash soaps are far softer, and do not set, the soft soap used for scrubbing and cleansing in many manufacturing processes, and also a few toilet creami and shaving pastes, being of this character.

It would occupy far too much time, and would, moreover, be outside the scope of this lecture, to go into the details of the manufacturing methods by which soap is made on the large scale, and if I give a rough idea of the general processes employed, it will be sufficient for the purpose.

Carbonate of soda is first converted into hydrate by dissolving it in water, and then boiling with quicklime. Quicklime consists of calcic oxide, and this, when put into the vat containing the sodic carbonate in solution, combines with water, forming calcic hydrate, which then reacts with the sodic carbonate, forming calcic carbonate or chalk, which being insoluble sinks as a mud to the bottom of the vessel, whilst sodic hydrate remains in solution.

$$
\left.\begin{array}{l}
\text { Calcic hydrate } \\
\text { Sodic carbonate }
\end{array}\right\}=\left\{\begin{array}{l}
\text { Sodic hydrate } \\
\text { Calcic carbonate. }
\end{array}\right.
$$

Of late years the soap-boilers have to a great extent bought the sodic hydrate direct from the manulacturer, and so have avoided this operation.

The solution of sodic hydrate, called caustic ley, is made in different strengths, and tallow is first boiled with a weak ley, and as the conversion into soap proceeds, so stronger leys are used until the whole of the fatty matter has been saponified.

If a strong ley had been used at first, the soap as it formed being insoluble in strong alkalies would have coated the surface of the fat and prevented its complete conversion.

If at the end of the saponification process, the alkaline solution is sufficiently strong, the soap will on standing separate as a fluid layer on the surface of the spent ley, which contains the glycerine set free during the saponification, but in any case separation can be rapidly brought about by adding salt to the liquid, when the soap being insoluble in salt water or brine, separates out and is removed and placed in moulds to harden.

The block of soap so cast is then cut first into slabs, and then again into bars.

A soap made in this way wath tallow or lard as the fatty matter, would be "white curd," whilst if yellow bar is required, rosin is added to the mixture of ley and soap after most of the fat has saponified.

When rosin is boiled with alkaline solutions, a compound is formed by the direct union of the resinous acids with the alliali, which strongly resembles ordinary soap, so that the yellow soap is really a mixture of fatty and rosin soap, and when the ingredients are of great purity, the product goes by the name of "Primrose" soap. Bar soaps so made on a large scale are, as a rule, the stock from which the various forms of toilet soap are

No. I 289 , voL. 50] made by processes intended to render them more attractive for personal use, but generally the consumer gets far better value for his money, and far less injury to his skin, by using a good "white curd" or "Primrose" soap than by employing a highpriced toilet soap, whilst cheap toilet soaps, especially cheap transparent soaps, should be studiously avoided.

The demand made by consumers for cheap soaps, which in many cases are sold retail at prices considerably below the wholesale market price for a true soap, has given rise to the introduction of highly watered soaps, caused to set hard by the addition during manufacture of sodic sulphate, which enables the manufacturer to make a so-called soap often containing less than 20 per cent. of true soap.

Any person desiring to obtain the fullest particulars as to the manufacturing details of the soap trade, cannot do better than consult Dr. C. R. Alder Wright's admirable treatise upon the subject.

Having got our soap, the next point is to try and gain an idea of the way in which it acts as a detergent.

Supposing we are fartunate enough to have a sample of pure neutral soap, we find that on dissolving some of it in water, it undergoes a partial decomposition into alkali, and fatty acid, this action being called the hydrolysis of soap.

The small quantity of alkali so set free, attacks the fatty matter which glues the dirt to the skin, and by dissolving it loosens and enables the water to wash off the particles of dirt.

If this were the only action, however, soap would have no ad. vantage over soda, a solution of which would equally well perform this part of the operation. As the soap decomposes and the alkali removes the grease and dirt, the fatty acid liberated simultaneously from the soap comes in contact with the newlycleansed skin, and not only softens and smooths it, but also neutralises any trace of free alkali, and so prevents irritation and reddening of the cuticle.

These are prohably the main actions by which soap cleanses, but other causes also play a subsidiary part. We know that a solution of soap causes a lather when a itated, this being due to the cohesive power given to the particles of which the liquid is built up by the presence of the soap, a phenomenon which also enables us to blow bubbles with the sozp solution on ac. count of the strength of the fine film of liquid, a property which is not found in water alone.

The power of cobesion which the soap solution possesses is in all probability an important factor in removing the particles of dirt from the skin at the moment that they are loosened by the action of the alkali. Prof. IV. Stanley Jevons suggested yet a fourth way in which the soap solution might act ; when finely divided clay is suspended in water, the microscope reveals the fact that the minute particles are in rapid movement, and hence settle but slowly in the liquid. This movement he christened pedetic action, and he observed that the addition of soap or silicate of soda - often used in soap - to the liquid, enormously increased this agitation of the particles, which would tend to aid the breaking away of the dirt particles the moment they were set free.

Many soaps, even among the varieties intended for the toilet, contain a considerable excess of free alkali, which being greater than the liberated fatty acids can neutralise, cause most painful irritation of the skin, as is testified to by the smarting which annoys the chin after the use of certain shaving soaps; and every Iady knows that an alkaline soap, when used for washing the hair, renders it harsh and brittle, and destroys the gloss, but in both cases a rapid rinse with water, containing a few drops of vinegar, will neutralise the free alkali and prevent much of the mischief:

We have now dealt with our grease solvents and dirt looseners, but wilbout the aid of water they would be use. less; and experience teaches us that the source of the water used for cleansing, has a great deal to do with its efficiency whether used with or without soap.

As the new-born rain-drops fall from the breaking clouds, they are practically pure water, containing at most traces of gaseous impurities which the mist has dissolved from the upper sirala of air whilst journeying in the form of cloud, and where the rain is collected in the open country, it gives us the purest form of natural water, healthful to drink, because it is highly. aerated, and free from all impurity, organic and inorganic, anck delightful to wash in because of its softness and the ease with which the soap gives a lather.

In towns, however, a very different state of things exists, as the 
rain in falling washes the air from a large proportion of the sus. pended organic matters inseparable from a crowded city, and also from the unburnt particles of carbon, which incomplete combustion allows to escape from our chimneys; and charged with these, it still collects more dirt of various kinds from the roofs of our houses, and finally finds its way into our water.butts as the semi-putrid sludge which often causes the true-bred cockney to wonder "if this so.called purest form of natural water is so foul, what on earth must the other forms of water be like?" If in the country the rain water is collected and stored in suitable reservoirs, then we have the most perfect water that can be obtained for washing and cleansing purposes.

In some hinds of water collected under what we might consider ideal circumstances, we find " a something" which acts as a check upon the cleansing action of the soap.

In Attica, close to Athens, on the slopes of Mlount Pentilicus, the Emperor Hadrian built some huge marble underground aqueducts to collect and lead the rain water down as a supply for Athens, the whole water-shed consisting of marble; this mountain being justly celebrated as the source from which the finest statuary marble is obtained. Here, falling through the clear southern air on to a collecting ground formed of the material which all ages have considered the most suitable for baths and reservoirs, one would expect the water to be like the pure rain water, absolutely free from dissolved solid impurities, and one of the best waters of its kind for washing purposes; yet not only does it waste a large amount of soap before a lather is obtained, but if we examine the channels through which it has for centurie; flowed down to the valley, we find that it has formed a heavy deposit, which collecting unchecked through long ages, has all but choked up the once spacious passages. A piece of this deposit I have obtained through the kindness of a friend, and on analysis it proves to be:-

\begin{tabular}{|c|c|c|c|c|}
\hline Calcic carbonate & $\cdots$ & $\cdots$ & $\cdots$ & $96.8 r$ \\
\hline Silica... $\quad \ldots$ & $\ldots$ & $\cdots$ & $\cdots$ & 0.49 \\
\hline Organic matter & $\cdots$ & $\ldots$ & $\cdots$ & I 40 \\
\hline Moisture $\quad \ldots$ & $\cdots$ & $\cdots$ & $\cdots$ & $1 \cdot 30$ \\
\hline
\end{tabular}

It is, in fact, a natural incrustation deposited by the water, and a similar action is seen in the formation of stalactites in many caverns, through the roof of which water charged with certain calcareous compounds has slowly found its way.

In the passage of the rain through the air small quantities of carbon dioxide or carbonic acid gas are dissolved from the atmosphere, whilst in slowly percolating through the surface soil on which it has fallen the water is brought in contact in the pores of the soil with far larger volumes of this gas, which is being continually generated there by the decomposing vegetation and other organic matter in a state of decay. Under these circumstances the water becomes highly charged with the gas, and sinks on through the ground until it comes in contact with some impermeable strata through which it cannot penetrate, and here it collects until a sufficient head of water has been formed for it to force its way along the strata to the surface of the earth, where it now appears as a spring, and during this passage through the earth it has dissolved everything that will yield to its own solvent action or to the activity of the carbon dioxide, which dissolved in water forms the weak carbonic acid, a compound which will dissolve many substances insoluble in the water itself, such as calcic carbonate, occurring in the soil as marble, limestone, or chalk, and also the carbonates of iron and magnesium. If we examine a spring water, we shall find that its dissolved impurities can be divided into two classes : for instance, taking the Kent water supplied at Greenwich, and obtained from deep wells in the chalk, we find its saline constituents in grains per gallon are :-

\begin{tabular}{|c|c|c|c|c|}
\hline Calcic carbonate ... & & & & $6 \cdot 30$ \\
\hline sulphate ... & $\ldots$ & & $\cdots$ & 5.37 \\
\hline Magnesic sulphate & $\ldots$ & $\ldots$ & $\ldots$ & 0.93 \\
\hline Magnesic nitrate ... & $\ldots$ & $\ldots$ & $\ldots$ & $\mathrm{I} \cdot 20$ \\
\hline Sodic chloride $\quad \ldots$ & $\ldots$ & ... & $\ldots$ & $2 \cdot 64$ \\
\hline Sodic nitrate $\quad \ldots$ & ... & ... & $\cdots$ & $1.2 I$ \\
\hline Silica, alumi & $\ldots$ & $\ldots$ & $\ldots$ & 0.97 \\
\hline
\end{tabular}

And of these the calcic sulphate, magnesium, and sodium salts are dissolved by the solvent action of the water in the same way that sugar would be, whilst the chief impurity, calcic

No. I 289 , VOL. 50] carbonate, is scarcely at all soluble in the water itself, 16,000 parts of pure water only dissolving one part of the carbonate, but is readily soluble in the carbonic acid, in the water which converts it into soluble calcic bicarbonate.

In the household, waters are roughly classified as hard or soft waters, and the property of hardness manifests itself, as a rule, to the bouseholder by its action upon soap, and also by the amount of "fur" which it causes in the kettle, these actions being due to calcic bicarbonate, calcic sulphate, and the magnesium salts present in it, all of which act upon soap and cause it to curd instead of forming a lather by converting the soluble sodic oleate and stearate into insoluble lime salts, whilst the bicarbonate by decomposing and depositing "chalk" causes the fur.

A more careful examination, however, reveals the fact that this property of hardness owes its origin to two different causes, for if we boil water until all the bicarbonate is broken up and the calcic carbonate deposited, the clear water left behind it is still hard, though to a far less extent, and will still decompose a certain proportion of soap. The hardness which can be got rid of by boiling is due to bicarbonate of lime, and sometimes also bicarbonate of magnesia, and is called "temporary hardness," whilst the hardness left after boiling the water is due to calcic sulphate and the soluble magnesium sulphate, chloride and nitrate, and is called "permanent hardness."

The relative hardness of waters is estimated by the amount of soap they will destroy, i.e. convert from the form of soluble sodic oleate and stearate into the condition of insoluble oleates and stearates of lime, and one grain of calcic carbonate or its equivalent in sulphate or salts of magnesia dissolved in a gallon of water, is said to equal $1^{\circ}$ of hardness.

The sample of Kent water of which an analysis has been given, contains $23^{\circ} 6$ grains of these salts, and would be said to have nearly $24^{\circ}$ hardness, 7.5 of which would be permanent and $16 \cdot 3$ temporary.

When it is considered that $1^{\circ}$ of hardness in water will waste to grains of soap per gallon of water used, we become aware of the economic importance of the kind of water employed in the household, a gallon of the Kent water, for instance, using up 236 grains or nearly half an ounce of soap before any becomes available to form a lather and exert a cleansing action upon the skin.

Glasgow used to have a hard water service, and when this was discontinued and the soft Loch Katrine water was supplied in its place, it made a difference of several thousands a year in the money expended in soap.

From these facts it is manifest that a soft water supply is an important factor in cheapening our cleansing processes, a pure rain water being the best attainable, whilst surface and river water are as a rule softer than spring water.

I have now discussed the chemistry of cleaning as fully as the time at my disposal will permit, and I hope the facts I have brought before you will have quickened your interest in soap, soda, and water, and will have helped to impress upon you that without proper processes of cleansing, the health of each unit, and therefore the prosperity of the masses, must suffer deterioration.

\section{UNIVERSITY AND EDUCATIONAL INTELLIGENCE.}

THE following pass list for the degree of Doctor of Science of London University has been issued :-Experimental Physics : Mr. Edwin Henry Barton. Chemistry : Mr. Bevan Lean, Mr. Thomas Kirke Rose, Mr. Arthur Landauer Stern. Botany : Miss Margaret Jane Benson. Zoology : Mr. Arthur Villey.

HER MAJESTY'S Commissioners for the Exhibition of 185 I have made the following appointments to science research scholarships for the year 1894 , on the recommendation of the autho. rities of the respective Universities and Colleges. The scholarships are of the value of $£ 150$ a year, and are tenable for two years (subject to a satisfactory report at the end of the first year) in any University at home or abroad, or in some other institution approved of by the Commissioners. The scholars are to devote themselves exclusively to study and research in some branch of science, the extension of which is important to the industries of the country :-Scholar nominated by the University of Edinburgh, John Carruthers Beattie; by the Univer- 